\title{
Modification of 2D Conventional Weaving Machine for the Fabrication of High Performance Woven Preforms: Part-I: Design and Manufacturing of Warp Creel
}

\author{
SANAM IRUM MEMON*, MAZHAR HUSSAIN PEERZADA*, RAFIQUE AHMED JHATIAL*, \\ RAJA FAHAD ASHRAF QURESHI*
}

RECEIVED ON 23.11.2018 REVISED ON 10.01.2019

\begin{abstract}
The Woven preforms are generally manufactured by weaving technique using either complex 3D weaving machines or especially designed patent machines. The advantage of conventional technique lies in the flexibility of yardage production and composite may be developed by lamination or directly using 3D multilayer structure. Due to the stiffer nature of high-performance fibers, the conventional weaving technology causes damage of fibers in general and strength and modulus in particular. The warp creel is one of the main elements of weaving machine which is responsible for such fiber damage due to inflexible unwinding of fiber spool caused by friction. Therefore, in this research, a warp creel with novel features has been designed and manufactured to replace the conventional warp beam for smooth processing of high performance fibers. For this purpose, different parts of the proposed warp creel were designed and manufactured, including creel frame and adjustable spindles. These parts were manufactured with different specifications and order to carry out the smooth processing of high-performance tow. All these parts were manufactured with MS steel. The developed warp creel was used for the production of highperformance fiber preforms. In this study, three different high-performance fibers (Carbon, Kevlar and Glass) were used to fabricate plain woven preforms. The main objective of this research is the preclusion of the fibers/filaments from deterioration from weaving mechanism. The results showed the minimum number of filaments of carbon tow being damaged. The use of MS steel material and highly polished parts resulted in least amount of frictional contacts which in turn improved the apparent quality of the formed preforms.
\end{abstract}

Key Words: Warp Creel, 2D Conventional Weaving Machine, High-Performance Fibers, Woven Preforms.

\section{INTRODUCTION}

$\mathrm{T}$ The textile preforms are the general class of engineering materials [1] manufactured to confirm desired shape and specific mechanical and structural characteristics. Many of textile preform manufacturing processes including weaving, braiding and knitting developed in ancient times are still used in remote areas of the world today. From these methods, conventional weaving is one of the most important preform manufacturing processes [2] but it has drawback of deterioration of mechanical properties of high-

Authors E-Mail: (sanam.irum@faculty.muet.edu.pk, mazhar.peerzada@faculty.muet.edu.pk, rafique.jhatial@faculty.muet.edu.pk, raja.ashraf@faculty.muet.edu.pk)

* Department of Textile Engineering, Mehran University of Engineering \& Technology, Jamshoro 
performance fibers such as Carbon, Glass and Aramid fibers. However, with the advent of the industrial age, rapid developments in machinery and textile manufacturing techniques have advanced the science of textiles [3]. Over the last decades, several textile technologies have been developed to manufacture textile preforms for fields such as aerospace, automotive, transport, sports, wind energy and off-shore. The aim was to improve the mechanical performance [4]. Due to design versatility woven preforms are playing important roles in meeting the high-performance demands for technical applications because the weaving technology is able to use a variety of raw materials and to convert them into products with various geometrical forms [5]. In conventional looms warp yarns are supplied from warp beam that contains thousands of individual warp yarns [6]. Fig. 1 shows conventional warp beam, is an iron rod when empty weighs up to $30 \mathrm{~kg}$. If it is loaded weighs up to $300 \mathrm{~kg}$ [7]; therefore, beams with this huge weight are not suitable for high-performance fiber weaving. Also for preform fabrication lesser number of warp yarns is required; thus, warp yarns or tow are supplied directly from creel which necessitates extra flexibility in unwinding and guiding fiber tow on its way to main weaving zone. The diameter of yarn is in microns; whereas, the width of high-performance fiber tow is $4-16 \mathrm{~mm}$. Moreover, the high-performance fibers are very delicate with zero twist which cannot be processed in conventional weaving machine because of friction with different loom parts and excessive tension. It is also known that the fibers get abraded against each other and with the loom machinery during weaving, and the resulting abrasion damage causes a reduction in yarn strength of between 30 and $50 \%$ depending on the type of yarn [8]. This research is based on designing and development of warp creel for manufacturing of textile preforms from high-performance fibers (Carbon, Kevlar, Glass etc) which has overcome the problem of spool unwinding and excessive friction in creel parts.

\subsection{MATERIAL}

For this research $2 \mathrm{D}$ conventional weaving machine was selected. The warp creel is designed and manufactured instead of warp beam for high performance fibers. All the components of creel portion are manufactured from MS steel, Nylon shaft (polymer), polished rod (MS steel shaft), and stainless steel wires $(2 \mathrm{~mm})$. The machine used for the manufacturing of all warp creel parts are cut-off machine DEWALT (D28720) German, Lathe machine, electronic arc welding machine.

\section{DESIGN OF DIFFERENT PARTS OF WARPCREEL}

The warp creel is used to unwind and feed the carbon tow to $2 \mathrm{D}$ conventional weaving machine to manufacture

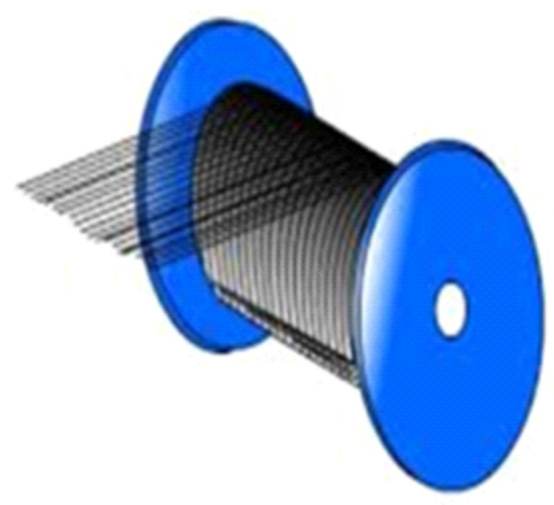

FIG. 1 CONVENTIONAL WARP BEAM

Mehran University Research Journal of Engineering \& Technology, Volume 39, No. 1, January, 2020 [p-ISSN: 0254-7821, e-ISSN: 2413-7219] 
woven preforms. The straight type warp creel with the capacity of 21 spindles, for holding high performance fiber tow spools. Seven polished rods are used and three spindle in each rod. Fig.2, 3 and 4 show the 2D, 3D and dimensions of warp creep. The design of warp creel consists of two major parts, creel frame and adjustable spindles.

\subsection{Creel Frame}

The creel frame was manufactured from MS steel. It consists of different parts. These parts were designed and manufactured from MS steel. The frame of creel was manufactured from MS steel square pipe of $38 \mathrm{~mm}$ diameter. The length and width of creel were $1829 \mathrm{~mm}$ and $1524 \mathrm{~mm}$ respectively. Seven polished rods were fixed to hold spindles, each rod contains three spindles. The diameter of each rod was kept 19.05mm. Fig.5 and 6 show 2D and $3 \mathrm{D}$ views of polished rods. The round clips were manufactured to hold rods. The length of clips was $140 \mathrm{~mm}$ and thickness was $4 \mathrm{~mm}$. The internal diameter of clips was $19.05 \mathrm{~mm}$. Fig. 7 and 8 show 2D and 3D views of warp creel clip. The four wheels of $63.5 \mathrm{~mm}$ in diameter with brakes were fitted at the bottom of the creel for adjusting the creel. Fig. 9 and 10 depicts 2D and 3D drawing of wheels. Table 1 shows the specifications below of all these components prepared for this study.

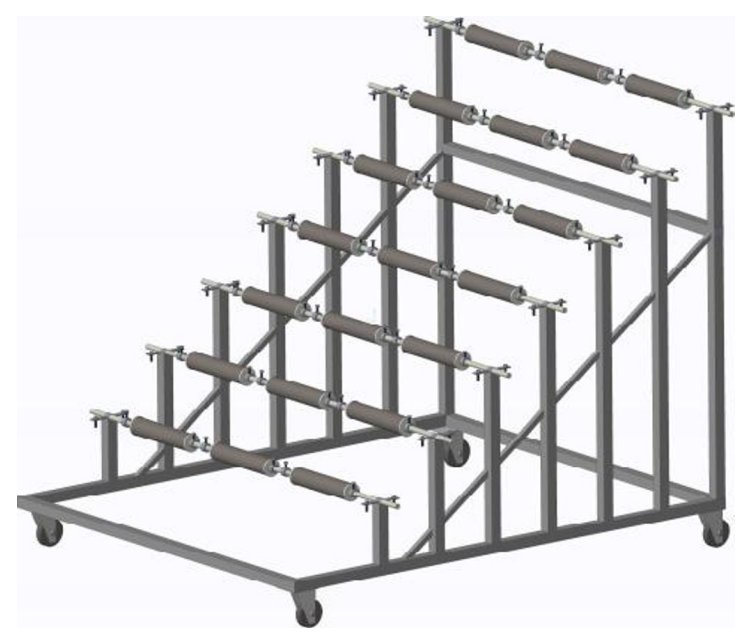

FIG.3 THREE-DIMENSIONAL VIEW OF WARP CREEL

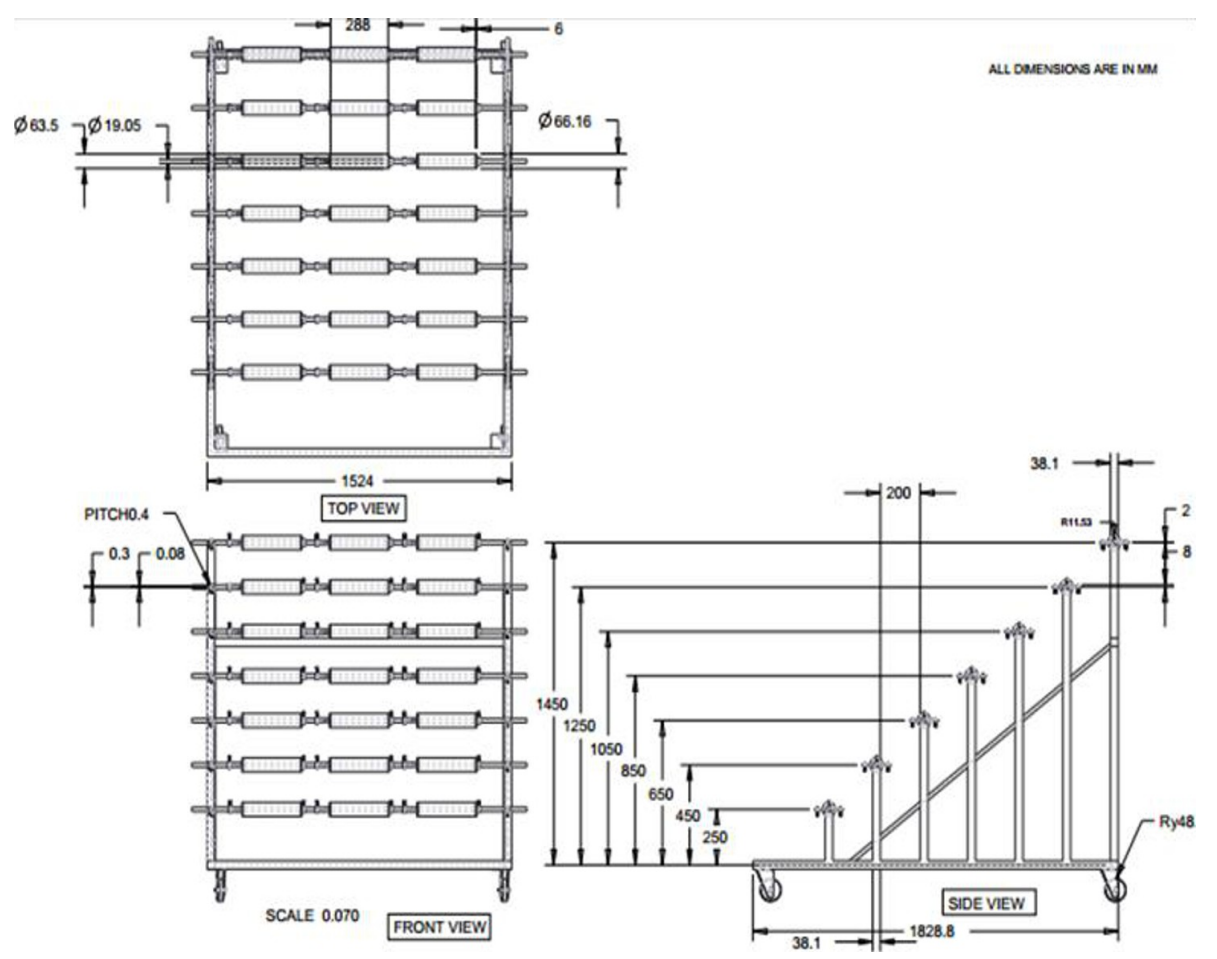

FIG.2 TWO-DIMENSIONAL VIEWS OF WARP CREEL

Mehran University Research Journal of Engineering \& Technology, Volume 39, No. 1, January, 2020 [p-ISSN: 0254-7821, e-ISSN: 2413-7219] 


\subsection{Adjustable Spindle}

The adjustable spindles were made from MS steel polished rods to hold the cheese of carbon tow packages for manufacturing of textile composite preforms. Fig.11 and 12 show 2D and 3D views of adjustable spindle. Its flexibility lies in its design to hold different package diameters. The $63.5 \mathrm{~mm}$ diameter nylon plates were used to hold and provide ease in the unwinding of carbon packages. The collar of nylon plate was $6 \mathrm{~mm}$ and the internal diameter was $78 \mathrm{~mm}$ with external diameter of $78 \mathrm{~mm}$. Fig. 13 and 14 show 2D and 3D views of round nylon plates. The hollow center of nylon plate was made with round bush attachment to move smoothly on the polished rod. The stopper bushes were used to stop the spindle to avoid excessive unwanted and reverse movement of spindle. Fig.15 and 16 show 2D and 3D views and dimensions of stopper. The round stopper bushes were made with nut and bolt. The nut and bolt are fixed on the top of the stopper bush to fix on the polished rod. The stopper bush is also adjustable. It depends upon the sizes of the spindle package. The stopper bush has internal diameter of $19 \mathrm{~mm}$ and external diameter of $32 \mathrm{~mm}$; whereas, it has thickness of $7 \mathrm{~mm}$. The springs were added to adjust the tension of the spindles. Figs. 17-19 show 2D and 3D drawings of spring. The diameter of spring was $19.05 \mathrm{~mm}$ and the thickness of wire of springs was $2 \mathrm{~mm}$. Table 2 shows the specifications.

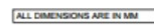

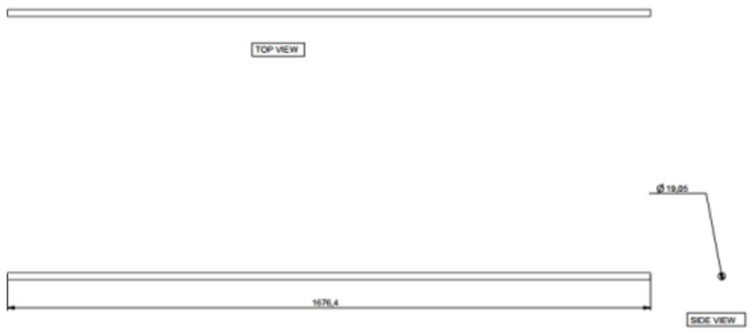

maniven

FIG.5 2D VIEW OF POLISHED ROD

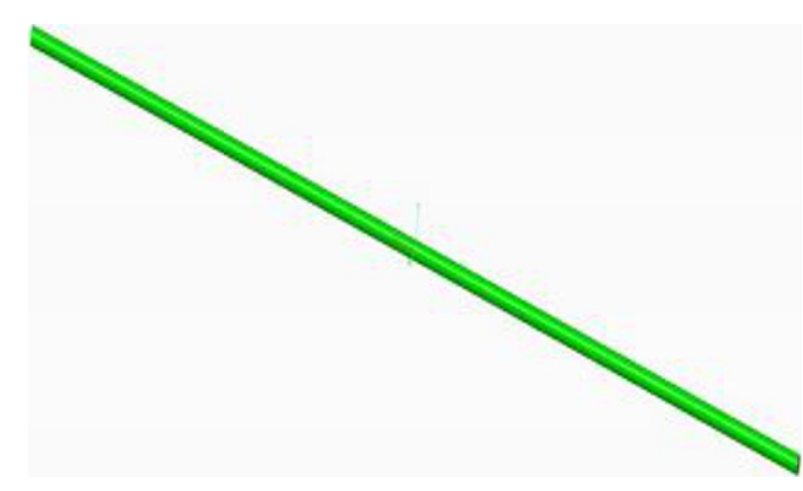

FIG.6 3D VIEW OF POLISHED ROD

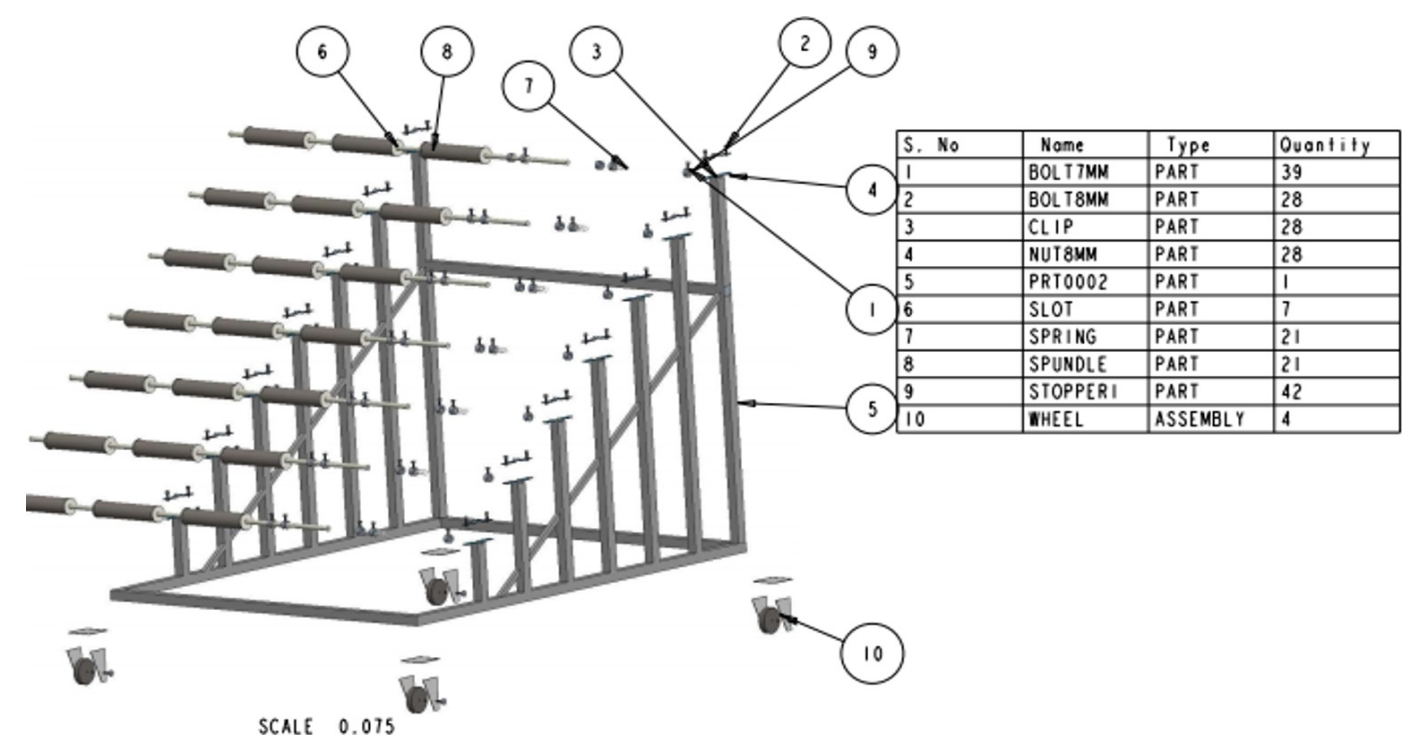

FIG.4 THREE DIMENSIONAL VIEW AND DIMENSIONS OF WARP CREEL

Mehran University Research Journal of Engineering \& Technology, Volume 39, No. 1, January, 2020 [p-ISSN: 0254-7821, e-ISSN: 2413-7219] 


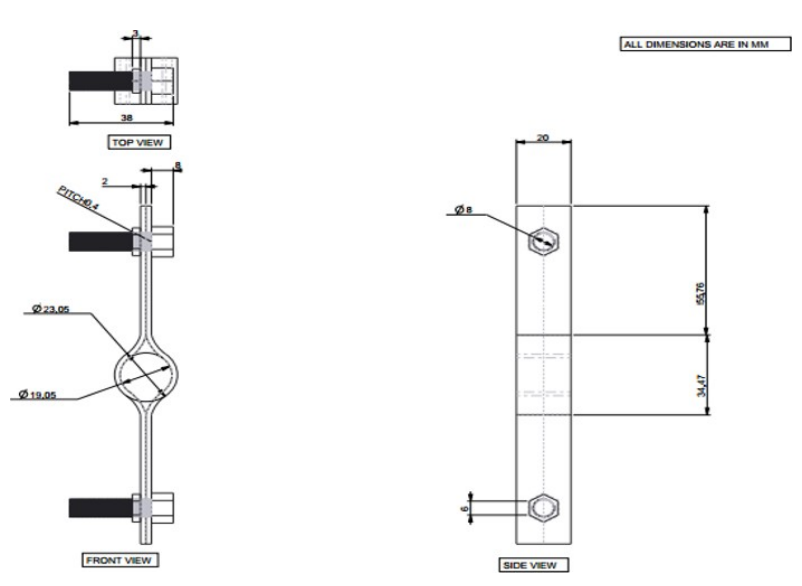

FIG.7 3D VIEW CLIP

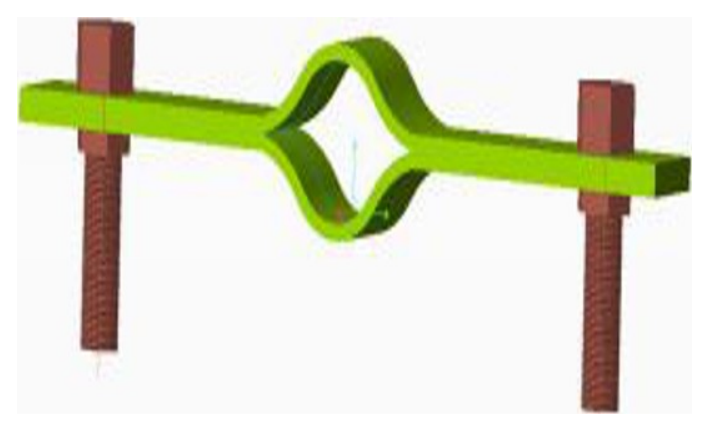

FIG.8 2D VIEWS OF WHEEL

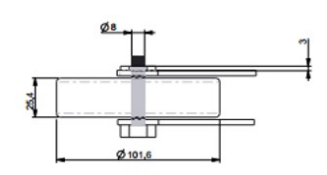

TOP VEN
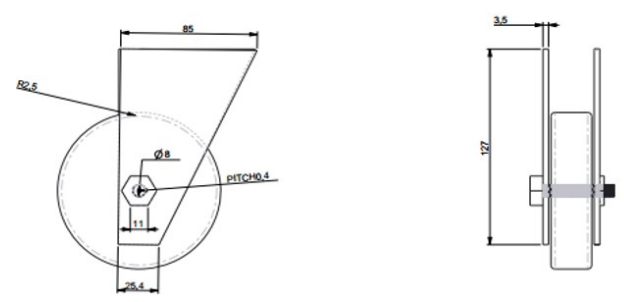

FIG.9 3D VIEW WHEEL

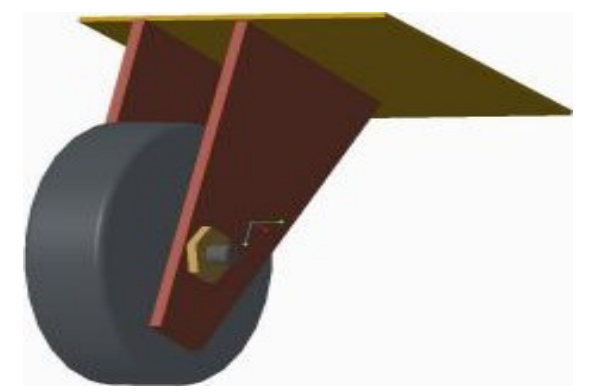

FIG.10 2D VIEWS OF ADJUSTABLE SPINDLE

AL DOMENSONSA AEE IN MU

(a)

roo neE

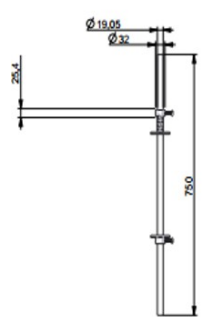

ERorvivew

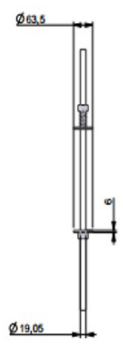

SoE NEW

FIG.11 3D VIEW OF ADJUSTABLE SPINDLE

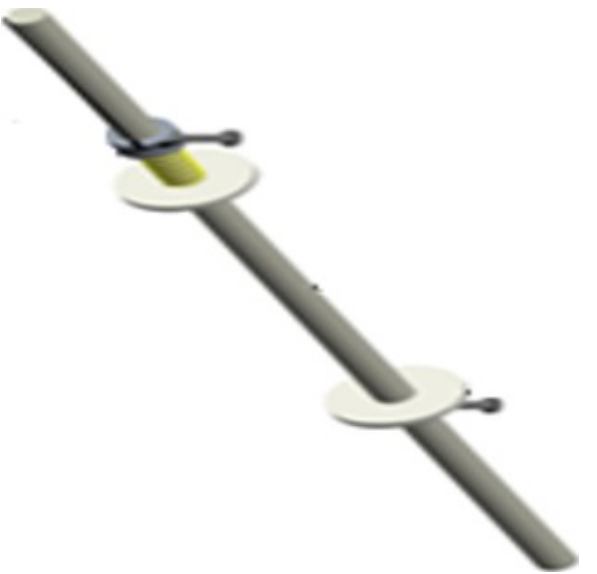

FIG.12. 3D VIEW OF ADJUSTABLE SPINDLE

TABLE 1 SPECIFICATION OF CREEL FRAME PARTS

\begin{tabular}{|c|c|c|c|c|c|}
\hline Parts & $\begin{array}{c}\text { Length } \\
(\mathrm{mm})\end{array}$ & $\begin{array}{c}\text { Width } \\
(\mathrm{mm})\end{array}$ & $\begin{array}{c}\text { Thickness } \\
(\mathrm{mm})\end{array}$ & $\begin{array}{c}\text { Internal Diameter } \\
(\mathrm{mm})\end{array}$ & $\begin{array}{c}\text { External Diameter } \\
(\mathrm{mm})\end{array}$ \\
\hline Square pipe & 1828.8 & 1524 & 2 & 38 & 40.2 \\
\hline Polished rods & 19.05 & 1524 & 2 & 19.05 & 19.02 \\
\hline Clips & 14 & 24 & 4 & 19.05 & 19.05 \\
\hline
\end{tabular}

Mehran University Research Journal of Engineering \& Technology, Volume 39, No. 1, January, 2020 [p-ISSN: 0254-7821, e-ISSN: 2413-7219] 


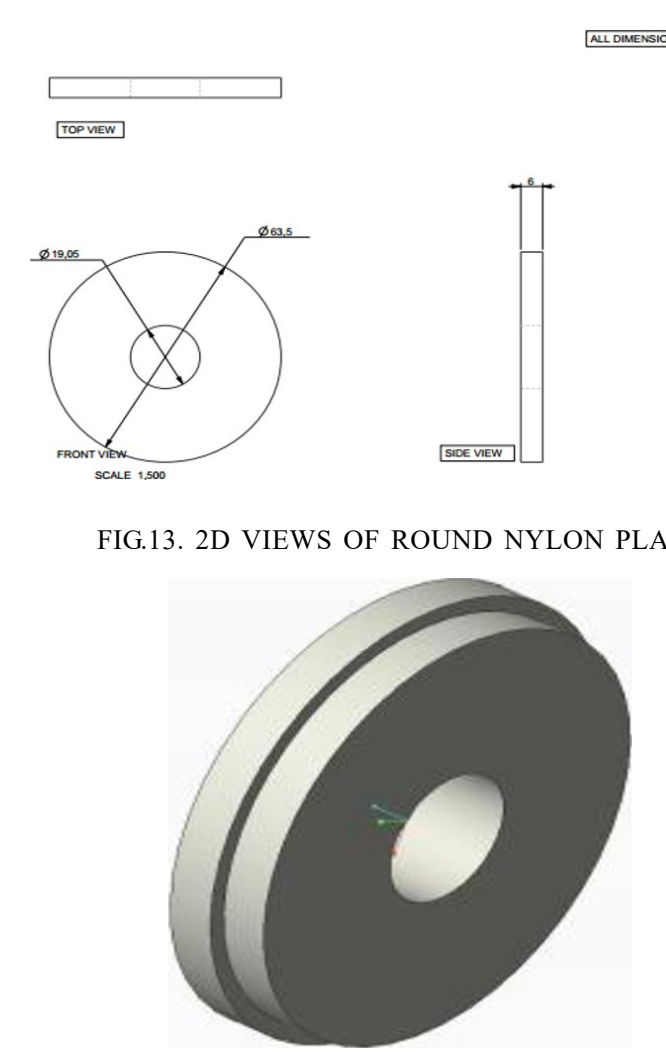

FIG.14 2D VIEWS OF ROUND NYLON PLATE

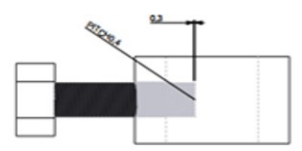

$$
\text { ricesent }
$$

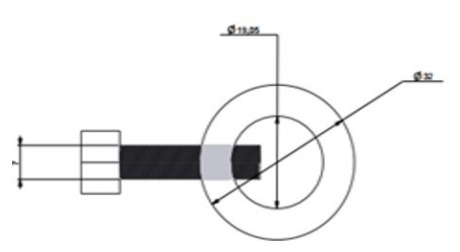

Bent ven

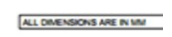

FIG.15 3D VIEW OF ROUND NYLON PLATE

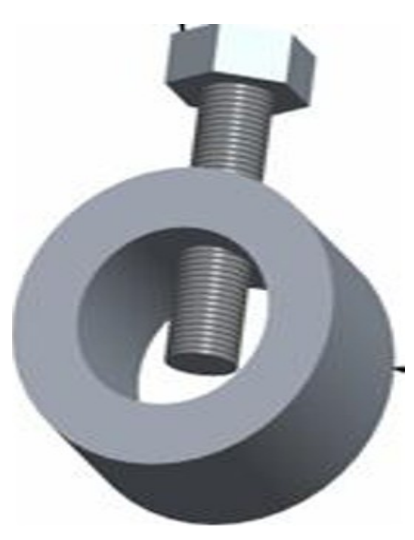

FIG.16 2D VIEWS OF STOPPER

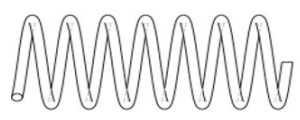

TOPVEN
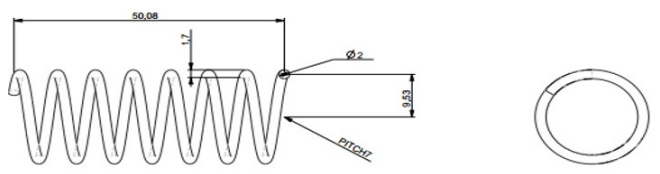

FRONT VEW

SIOE VEW

FIG.17 3D VIEW OF STOPPER

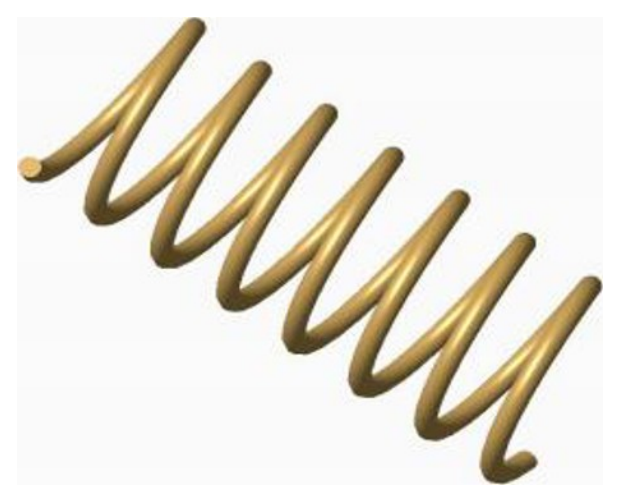

FIG.18 2D VIEWS OF SPRING

TABLE 2 SPECIFICATION OF ADJUSTABLE SPINDLE PARTS

\begin{tabular}{|c|c|c|c|c|c|}
\hline Parts & $\begin{array}{c}\text { Length } \\
(\mathrm{mm})\end{array}$ & $\begin{array}{c}\text { Width } \\
(\mathrm{mm})\end{array}$ & $\begin{array}{c}\text { Thickness } \\
(\mathrm{mm})\end{array}$ & $\begin{array}{c}\text { Internal Diameter } \\
(\mathrm{mm})\end{array}$ & $\begin{array}{c}\text { External Diameter } \\
(\mathrm{mm})\end{array}$ \\
\hline Round nylon plate & 28 & 18 & 82 & 78 & 78 \\
\hline Round nylon plate bush & 24 & 18 & 5 & 19 & 24 \\
\hline Stopper bush & 10 & 18 & 7 & 19 & 32 \\
\hline Spring & 24 & 55 & 2 & 19.05 & 23 \\
\hline
\end{tabular}

Mehran University Research Journal of Engineering \& Technology, Volume 39, No. 1, January, 2020 [p-ISSN: 0254-7821, e-ISSN: 2413-7219] 
After the completion of designing, manufacturing and assembling phases of different parts of warp creel, its performance was evaluated during production of $2 \mathrm{D}$ preforms using $2 \mathrm{D}$ conventional weaving machine. The performance of newly designed creel was very good when tested for three different high-performance fibers (Carbon, Kevlar and Glass) which were used to manufacture plain woven preforms. Figures. 19-21 show plain weave design (1/1) woven preforms. Table 3 shows different parameters of woven preforms construction.

\section{DETAILS OF PREFORMS CONSTRUCTION}

For this study warp tows of carbon $12 \mathrm{k}$ denier, Kevlar 1130dtex and glass 4200 tex were selected. The preform structure was plain weave of $(1 / 1)$.

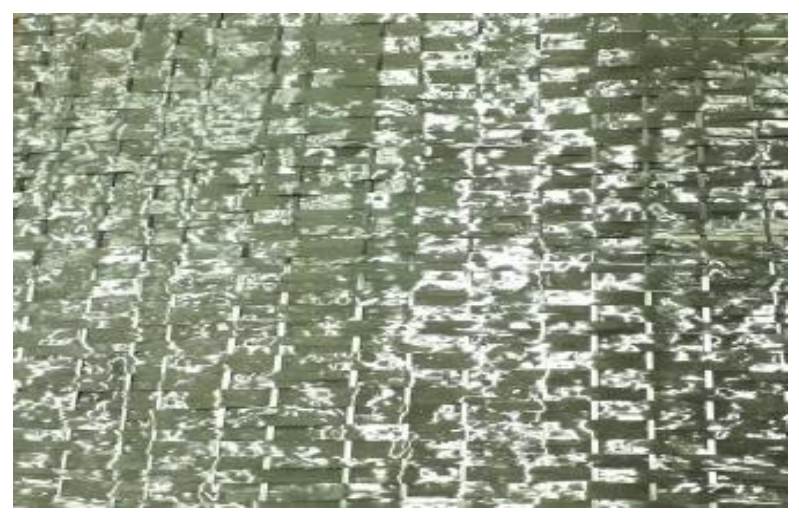

FIG.19 3D VIEW OF SPRING
Quality of Carbon preform $=\frac{\text { warp count } \times \text { weft count }}{\text { ends } / \text { inch } \times \text { picks } / \text { inch }} \times$ width of fabric

$$
\begin{aligned}
& =12000 \times 12000 / 2 \times 5 \times 21 \\
& =144,000,000 / 10 \times 21 \\
& =14,400,000 \times 21 \\
& =302,400,000
\end{aligned}
$$

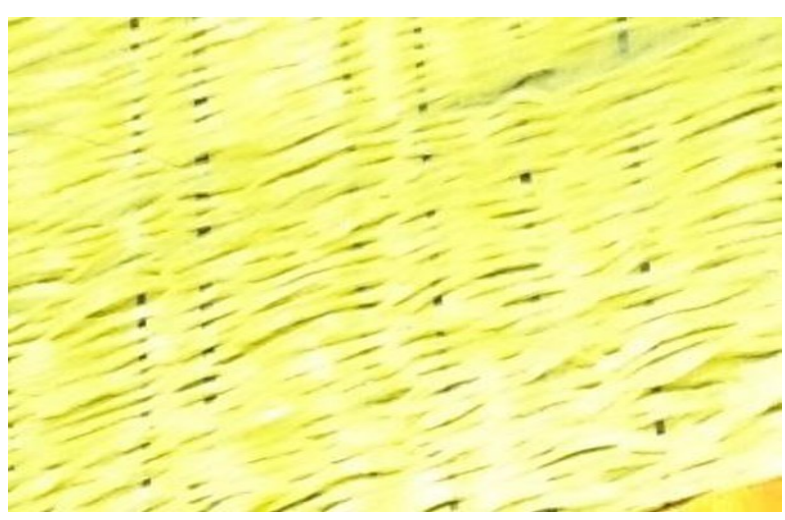

FIGURE 20 CARBON PREFORM PLAIN WEAVE (1/1)

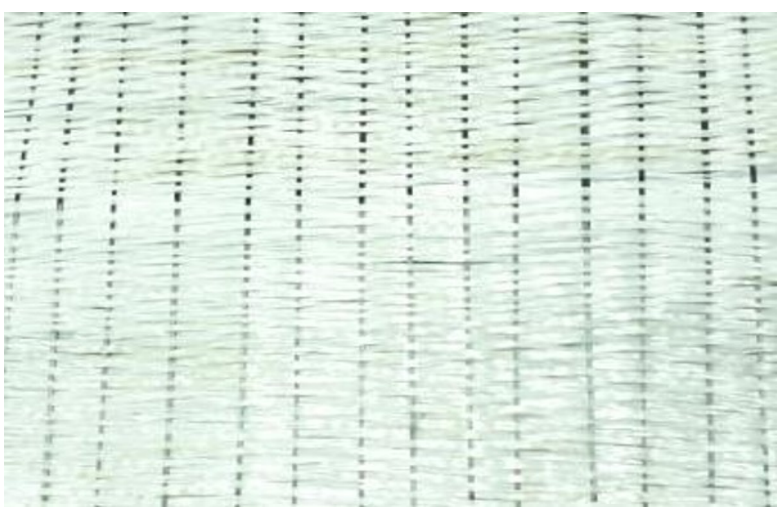

FIGURE 21 KEVLAR PREFORM PLAIN WEAVE (1/1)

TABLE.3 WOVEN PREFORM PARAMETERS

\begin{tabular}{|c|c|c|c|c|}
\hline S. No. & High Performance fibers & Carbon preform & Kevlar preform & Glass preform \\
\hline 1. & Weave Design & Plain Weave $(1 / 1)$ & Plain weave $(1 / 1)$ & Plain weave(1/1) \\
\hline 2. & Warp Tow & Carbon & Carbon & Carbon \\
\hline 3. & Weft Tow & Carbon & Kevlar & Glass \\
\hline 4. & Warp count & 12000 & 12000 & 12000 \\
\hline 5. & Weft count & 12000 & 1130 & 2200 \\
\hline 6. & Ends/inch & 2 & 2 & 11 \\
\hline 7. & Picks/inch & 5 & 8 & 21 \\
\hline 8. & Fabric width & 21 & 21 & 2 \\
\hline
\end{tabular}

Mehran University Research Journal of Engineering \& Technology, Volume 39, No. 1, January, 2020 [p-ISSN: 0254-7821, e-ISSN: 2413-7219] 
Quality of Kevlar preform $=\frac{\text { warp count } \times \text { weft count }}{\text { ends } / \text { inch } \times \text { width of fabric }}$

$$
\begin{aligned}
& =12000 \times 1130 / 2 \times 5 \times 21 \\
& =13,560,000 / 10 \times 21 \\
& =1,356,000 \times 21 \\
& =28,476,000
\end{aligned}
$$

Quality of Glass preform $=\frac{\text { warp count } \times \text { weft count }}{\text { ends } / \text { inch } \times \text { picks } / \text { inch }} \times$ width of fabric $=12000 \times 4200 / 2 \times 11 \times 21$

$=50,400,000 / 22 \times 21$

$=2,290,909.09 \times 21$

$=48,109,090.90$

Total no. of ends: 21

\section{CONCLUSION}

An innovative work of manufacturing warp creel with some unique and specific attributes has been successfully performed. While replacing the conventional complex warp beam, the newly designed warp creel showed excellent features. The main objective of this research was the preclusion of the fibers/filaments from deterioration from weaving mechanism. The results showed the minimum number of filaments of carbon tow being damaged. The use of MS steel material and highly polished parts resulted in least amount of frictional contacts which in turn improved the apparent quality of the formed preforms.

\section{ACKNOWLEDGMENT}

The authors are grateful to the staff of Weaving Laboratory, Department of Textile Engineering, and Mechanical Workshop, Mehran University of Engineering \& Technology, Jamshoro, Pakistan, for their kind support and guidance, and providing financial support and required resources to carry out this research.

\section{REFERENCES}

[1] Horrocks, A.R.; and Anand, S.C. (2000), Hand Book of Technical Textiles, 1ST edition, Cambridge, UK: Wooden head, 2000, ISBN 1-855-73385-4, PP.264-265.

[2] Toufique Ahmed et al, 2017. "The effect of backrest roller on warp tension inmodern loom" esj, 2017, v.13, no. 9 , pp. 127.

[3] Kamiya, Ryuta.; cheeseman, Bryan, A.; Popper, peter.; chou, tsu-wei. (2000), "Some recent advances in the fabrication and design of three-dimensional textile performs: a review" Journal of composite science and technology, V.60,2000,PP.33-47.

[4] Brandt, J.; Drechsler, K.; Arendts, F.J. (1996), "Mechanical performance of composites based on various three-dimensional woven-fiber preforms" Journal of Composites Science and Technology, V.56, 1996, pp. 381-386.

[5] Wilson, J. (2001), Handbook of Textile Design: principles, processes and practice. UK: Wood- head Publishing, 2001, ISBN 1-855-73573-3, PP.1-2.

[6] Kevin William Ray and Eric Lee Booth, 2017. "woven geo-textile filtration fabrics including core - sheath spun yarns", US patent, 2017, patent no. 0354907 A1

[7] V. Praveen, 2018, "Warp Beam Carrier for Power Looms", International Research Journal of Engineering and Technology (IRJET), 2018, Volume: 05 Issue: 03, pp. 438-440.

[8] S. Rudov-Clark et al, 2003, "Fiber damage in the manufacture of advanced three-dimensional woven composites" Journal of Composites: Part A, 2003, V. 34, pp. 963-970. 